\title{
Epigenetic inactivation of miR-9 family microRNAs in chronic lymphocytic leukemia - implications on constitutive activation of NFkB pathway
}

\author{
Lu Qian Wang ${ }^{1}$, Yok Lam Kwong ${ }^{1}$, Chi Shan Bonnie Kho ${ }^{2}$, Kit Fai Wong ${ }^{3}$, Kwan Yeung Wong ${ }^{1}$, Manuela Ferracin ${ }^{4}$, \\ George A Calin ${ }^{5}$ and Chor Sang Chim ${ }^{1^{*}}$
}

\begin{abstract}
Background: The miR-9 family microRNAs have been identified as a tumor suppressor miRNA in cancers. We postulated that miR-9-1, miR-9-2 and miR-9-3 might be inactivated by DNA hypermethylation in chronic lymphocytic leukemia (CLL).

Methods: Methylation of miR-9-1, miR-9-2 and miR-9-3 was studied in eight normal controls including normal bone marrow, buffy coat, and CD19-sorted peripheral blood B-cells from healthy individuals, seven CLL cell lines, and seventy-eight diagnostic CLL samples by methylation-specific polymerase chain reaction.

Results: The promoters of miR-9-3 and miR-9-1 were both unmethylated in normal controls, but methylated in five (71.4\%) and one of seven CLL cell lines respectively. However, miR-9-2 promoter was methylated in normal controls including CD19 + ve B-cells, hence suggestive of a tissue-specific but not tumor-specific methylation, and thus not further studied. Different MSP statuses of miR-9-3, including complete methylation, partial methylation, and complete unmethylation, were verified by quantitative bisulfite methylation analysis. 5-Aza-2'-deoxycytidine treatment resulted in miR-9-3 promoter demethylation and re-expression of pri-miR-9-3 in 183-E95 and WAC3CD5+ cells, which were homozygously methylated for miR-9-3. Moreover, overexpression of miR-9 led to suppressed cell proliferation and enhanced apoptosis together with downregulation of NFKB1 in 183-E95 cells, supporting a tumor suppressor role of miR-9-3 in CLL. In primary CLL samples, miR-9-3 was detected in 17\% and miR-9-1 methylation in none of the patients at diagnosis. Moreover, miR-9-3 methylation was associated with advanced Rai stage ( $\geq$ stage 2) $(P=0.04)$.
\end{abstract}

Conclusions: Of the miR-9 family, miR-9-3 is a tumor suppressor miRNA relatively frequently methylated, and hence silenced in CLL; whereas miR-9-1 methylation is rare in CLL. The role of miR-9-3 methylation in the constitutive activation of NFKB signaling pathway in CLL warrants further study.

Keywords: microRNA, miR-9-3, Tumor suppressor, DNA methylation, NFkB, Chronic lymphocytic leukemia

\section{Introduction}

DNA methylation refers to the chemical modification of the cytosine ring in a $\mathrm{CPG}$ dinucleotide by the addition of a methyl group $(-\mathrm{CH} 3)$ to the number 5 carbon of the cytosine pyrimidine ring in the CpG dinucleotide, resulting in the formation of 5-methylcytosine [1]. Global DNA hypomethylation, but aberrant, gene-specific DNA

\footnotetext{
* Correspondence: jcschim@hku.hk

'Department of Medicine, Queen Mary Hospital, The University of Hong Kong, Hong Kong, China

Full list of author information is available at the end of the article
}

hypermethylation of the promoter-associated CpG islands of tumor suppressor genes (TSGs), is a hallmark of many human cancers [2,3]. Methylation of multiple TSGs has involved in the dysregulation of signaling pathways in leukemia, lymphoma and myeloma, including cell cycle (CDKN2A/B), apoptosis (DAPK1/CDKN2A/APAF1), JAK/ STAT signaling and WNT signaling; thereby indicating the importance of TSGs methylation in the pathogenesis of hematological cancers [4-6]. Of note, the DNA hypermethylation in TSGs, such as DAPK1, ID4, SFRP1, TWIST2 and $Z A P 70$, has been identified to play a role in the

\section{Biomed Central}

(c) 2013 Wang et al.; licensee BioMed Central Ltd. This is an open access article distributed under the terms of the Creative Commons Attribution License (http://creativecommons.org/licenses/by/2.0), which permits unrestricted use, distribution, and reproduction in any medium, provided the original work is properly cited. 
pathogenesis or prognosis of chronic lymphocytic leukemia (CLL) [7-11].

Mature microRNA (miRNAs) are endogenous, singlestranded, non-protein-coding small RNAs measuring 19 to 25 nucleotides (nts), which suppress the expression of proteins that they target $[12,13]$. In carcinogenesis, miRNAs can be categorized into either oncogenic (oncomirs) or tumor suppressor miRNAs [14,15]. Recently, tumor suppressor miRNAs have shown to be silenced by aberrant DNA hypermethylation in cancers [1,16,17]. Furthermore, previous studies also identified methylation of some tumor suppressor miRNAs, including $m i R$ 203, miR-124-1, miR-181a/b, miR-107 and miR-424, to be involved in CLL leukemogenesis [18].

In humans, there are three independent miR-9 genes (miR-9-1 on chromosome 1 ; miR-9-2 on chromosome 5 and $m i R-9-3$ on chromosome 15), with identical mature $m i R-9$ sequence. In cancers, $m i R-9$ could be either oncomir or tumor suppressor miRNA, depending on the type of cancers or tissues [19,20]. For instance, overexpression of $m i R-9$ has been shown to enhance metastasis or invasion in breast cancer cells or glioblastoma, identifying its oncogenic role [21-23]. Conversely, miR-9 has been shown to target and repress $\mathrm{NF}_{\kappa} \mathrm{B} 1$ translation in ovarian tumor cells by binding to the 3 ' untranslated region (3' UTR) of the $N F \kappa B 1$ mRNA, leading to inhibition of cell proliferation; hence demonstrating a tumor suppressor function [24].

In this report, we studied methylation of $m i R-9-3$, in addition to $m i R-9-1$ and $m i R-9-2$ in a representative cohort of CLL to define its pathogenetic role.

\section{Materials and methods Patient samples}

Bone marrow samples were obtained from 78 CLL patients at diagnosis. The diagnosis of CLL was made according to the WHO Classification, based on classical morphology, low level of expression of light-chain-restricted surface immunoglobulin, and concomitant expression of CD5 and CD23 as demonstrated by flow cytometry $[25,26]$. Of the 78 CLL patients, there were 51 male $(65.4 \%)$ and 27 female (34.6\%) patients at a median age of 65 years (range: 37-91 years). The median presenting lymphocyte count was $18 \times$ $10^{9} / \mathrm{L}$ (range: $10-540 \times 10^{9} / \mathrm{L}$ ). Apart from 8 patients with insufficient Rai stage data, there were 42 (60.0\%) limited Rai stage (<stage II) and 28 (40.0\%) advanced Rai stage ( $\geq$ stage II) patients. Among the 53 patients with cytogenetic information, 13 (24.5\%) carried high/intermediate-risk cytogenetic aberrations [del(17p), $\mathrm{N}=2 ; \operatorname{del}(11 \mathrm{q}), \mathrm{N}=2$; trisomy 12, $\mathrm{N}=9$ ] and 40 (75.5\%) carried low/standard-risk cytogenetic alterations [del(13q), $\mathrm{N}=12$; normal karyotype, $\mathrm{N}=21$; other karyotypic changes, $\mathrm{N}=7$ ]. The median overall survival (OS) of this cohort was 69 months. The median OS of those with advanced Rai stage and limited Rai stage were 49 and 111 months respectively $(\mathrm{P}=0.006)$. Furthermore, the median OS for those with or without high/intermediate-risk karyotype were 28 months and 111 months respectively $(\mathrm{P}=0.003)$. Samples were obtained with written informed consent, and the study was approved by the Institutional Review Board of Queen Mary Hospital and in accordance with the Declaration of Helsinki.

\section{Cell lines and culture}

The human CLL cell lines CLL-AAT and MEC1 were purchased from American Type Culture Collection (Manassas, USA) and Deutsche Sammlung von Mikroorganismen und Zellkulturen Deutsche GmbH (DMSZ) (Braunschweig, Germany) respectively. MEC2, I83-E95 and WAC3CD5+ were kindly provided by Dr John C. Byrd, Department of Medicine, Ohio State University [27,28]. HG3 and 232B4 were kind gifts from Prof. Anders Rosén, Department of Clinical \& Experimental Medicine, Linköping University $[28,29]$. Cell cultures were maintained in RPMI medium 1640 , supplemented with $10 \%$ fetal bovine serum, $50 \mathrm{U} / \mathrm{ml}$ penicillin, and $50 \mu \mathrm{g} / \mathrm{ml}$ streptomycin (Invitrogen, Carlsbad, CA, USA) in a humidified atmosphere of $5 \% \mathrm{CO}_{2}$ at $37^{\circ} \mathrm{C}$.

\section{Methylation-specific polymerase chain reaction (MSP)}

DNA was extracted from seventy-eight bone marrow samples of CLL at diagnosis, seven cell lines and eight normal controls (CD19 sorted peripheral blood B cells from healthy donors, $\mathrm{N}=3$; peripheral blood buffy coats from healthy donors, $\mathrm{N}=2$; and bone marrow buffy coats from healthy donors, $\mathrm{N}=3$ ) by the QIAamp DNA Blood Mini Kit (QIAGEN, Germany). The MSP for aberrant gene promoter methylation was performed as described in detail previously [30]. Each sample was amplified with two sets of primers, one set for methylated DNA (methylated MSP) and one set for unmethylated DNA (unmethylated MSP). Treatment of DNA with bisulfite for conversion of unmethylated cytosine to uracil (but unaffecting methylated cytosine) was performed with the EpiTect Bisulfite Kit kit (QIAGEN, Germany). Details of primers and conditions for MSP of $m i R-9-1, m i R-9-2$ and $m i R-9-3$ were given in Additional file 1: Table S1.

\section{Quantitative bisulfite pyrosequencing}

DNA was treated with bisulfite and used as template. Primers for pyrosequencing were used to amplify the promoter region, which was overlapped with the amplicon of MSP. Primers were designed using PSQ Assay Design software (Biotage). Forward primer: 5'-GAAGGGGGTTGG GATTTGA-3'; Reverse primer: 5'-ATTTCTCCCCTACT CCCC-3'; condition: $2 \mathrm{mM} / 61^{\circ} \mathrm{C} / 50 \mathrm{X}$. A stretch of DNA with 9 adjacent $\mathrm{CpG}$ dinucleotides was pyrosequenced by sequencing primer: 5'-ATGGGAGTTTGTGAT-3'. 


\section{5-Aza-2'-deoxycytidine (5-AzadC) treatment}

I83-E95 and WAC3CD5+ cells at log-phase were cultured in six-well plates at a density of $1 \times 10^{6}$ cells $/ \mathrm{ml}$, with $0.5 \mu \mathrm{M}$ of 5 -AzadC (Sigma-Aldrich, St. Louis, MO, USA) for 5 days respectively, as described [31]. Fresh 5-AzadC was replaced every 24 hours. I83-E95 and WAC3CD5+ cells on day 0 and day 5 of 5 -AzadC treatment were harvested respectively.

\section{Quantification of pri-miR-9-3 and miR-9}

According to the manufacturer's instructions, total RNA was isolated using the mirVana miRNA Isolation Kit (Ambion, Austin, TX, USA). For quantification of primiR-9-3, miRNA was reversely transcribed by the QuantiTect Reverse Transcription Kit (QIAGEN, Valencia, CA), and quantified using the TaqMan Pri-miRNA Assay (ABI, Foster City, CA). GAPDH was used as reference for data analysis using the $2^{-\Delta \Delta C T}$ method [32]. Moreover, miR-9 was quantified by the TaqMan MicroRNA RT Kit, and TaqMan MicroRNA Assay Kit. RNU48 was chosen as reference using the $2^{-\Delta \Delta C T}$ method [32].

\section{Overexpression of miR-9 precursor}

According to the manufacturers' instructions, precursor miR-9 mimic (final concentration $100 \mathrm{nM}$ ) (Ambion, Austin, TX, USA) was transfected into $1 \times 10^{6}$ I83E95 cells and WAC3CD5+ cells respectively, using XtremeGENE siRNA Transfection Reagent (Roche, Basel, Switzerland), as described [33]. Non-targeting oligonucleotide mimic was used as the negative control.

\section{Cell proliferation, viability analyses}

The MTT method was used to determine cellular proliferation [34]. Cells were seeded in a 96-well microtitre plate at $2.5 \times 10^{4} /$ well in $100 \mu \mathrm{l}$ of medium. At the assay test time point 48 hours after transfection, $10 \mu \mathrm{l}$ of 5 $\mathrm{mg} / \mathrm{ml} \mathrm{MTT} \mathrm{reagent} \mathrm{was} \mathrm{added} \mathrm{to} \mathrm{each} \mathrm{well} \mathrm{and} \mathrm{incu-}$ bated for 4 hours. Then each well was added with $100 \mu \mathrm{l}$ dimethyl sulfoxide (DMSO), followed by the measurement of absorbance at $550 \mathrm{~nm}$ with reference to 650 $\mathrm{nm}$. Cellular viability assay was performed by the Trypan blue dye exclusion assay under microscope. Dead cells $(\%)=($ total number of dead cells per microscopic field $/$ total number of cells per microscopic field) $\times 100$. Five random microscopic fields were counted in each sample.

\section{Cellular apoptosis analysis}

Cell apoptosis was assessed by flow cytometry using FITC Annexin V and PI staining as described previously [35]. FITC Annexin V Apoptosis Detection Kit I (BDPharmingen) was used here. $1 \times 10^{6}$ I83-E95 or WAC3CD5+ cells were washed with cold PBS and resuspended in $100 \mu \mathrm{l}$ binding buffer with $5 \mathrm{ul}$ of Annexin V and $5 \mathrm{ul} \mathrm{PI}$, and then incubated for 15 minutes at room temperature in the dark. After adding $400 \mu$ l binding buffer to each tube, samples were analyzed by flow cytometry (BD FACS Canto II). FITC Annexin V positive, PI negative or FITC Annexin V positive, PI positive cells were counted as apoptosis cells.

\section{Western blot for NFKB1}

After 48 hours transfection, I83-E95 cells were harvested and lysed in RIPA buffer (50 mM Tris- $\mathrm{HCl}, \mathrm{pH} 7.4,150$ $\mathrm{mM} \mathrm{NaCl}, 0.2 \%$ SDS, 1\% Triton X-100, 2 mM EDTA). Protein lysates were separated on 10\% SDS-PAGE and blotting were performed on a $0.2 \mu \mathrm{m}$ nitrocellulose membrane (Bio-Rad, Hercules, CA). The membranes were incubated with NFkB1 (1:1000; Santa Cruz, CA) or anti-actin (1:5000; Sigma-Aldrich, USA) primary antibody at $4^{\circ} \mathrm{C}$ overnight. Then membranes were washed and incubated with anti-rabbit horseradish peroxidase conjugate secondary antibody at room temperature for 1 hour. Protein signals were detected by ECL plus Western blotting detection reagents (Amersham Biosciences, Buckinghamshire, UK) and exposed to X-ray film.

\section{Statistical analysis}

In CLL, the association of miR-9-3 methylation status with continuous variables (such as mean age, mean lymphocyte counts, diagnostic hemoglobin or platelet counts) and categorical variables (gender, Rai stage or high-risk karyotypes) were analyzed by student's t-test and chi-square test (or Fisher's exact test) respectively. OS is assessed from the date of diagnosis to the date of last follow-up or death. OS of patients with limited Rai stage (stages 0, I and II) was compared with those with advanced Rai stage (stages III and IV). Furthermore, OS of patients with high-risk karyotypes [del(17p), del(11q) or trisomy 12] was compared to those with standard-risk karyotypes [del(13q), normal karyotype or other karyotypic changes]. The mean values of MTT assay, Trypan blue exclusion assay, FITC Annexin V and PI staining apoptosis analysis in I83-E95 or WAC3CD5+ cells transfected with precursor miR-9 mimic were compared to those transfected with the scrambled oligo by student's t-test. Survival was plotted by the Kaplan-Meier method and compared by the log-rank test. All $\mathrm{P}$ values were two-sided.

\section{Results \\ MSP \\ Controls}

None of the 8 normal controls (N1 to N8) showed aberrant methylation of $m i R-9-3$ and $m i R-9-1$ (Figure 1A). Expected MSP results (normal DNA: U-MSP positive/ M-MSP negative; methylated DNA: U-MSP negative/MMSP positive) were obtained in the positive and negative controls. Moreover, direct sequencing of the miR-9-3 

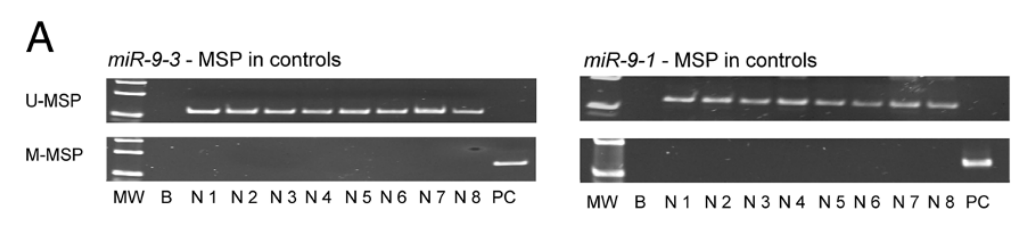

\section{B}

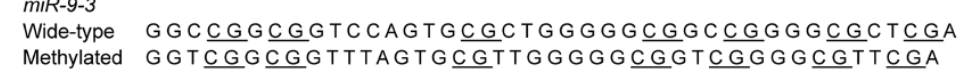

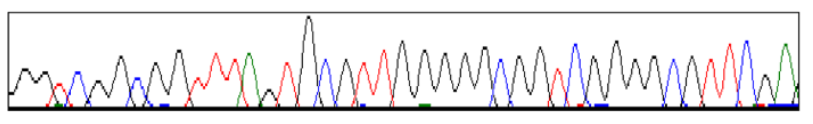

miR-9-1

Wide-type $\underline{\underline{C G A C A C}} \underline{\mathrm{CGACC}} \underline{\mathrm{CGACCACG}} \underline{\mathrm{CGCCAACTCAAAAAAACGCTA}}$

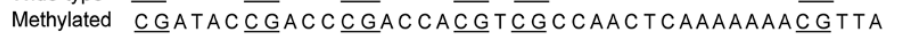

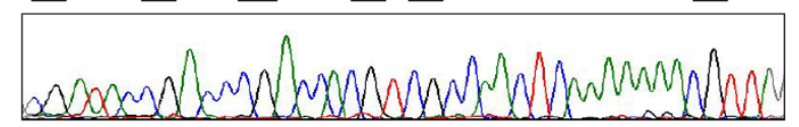

MW: Marker; B: Reagent blank; N1 to N3: CD19 sorted B cells of the peripheral blood from healthy donors; N4 to N5: Peripheral blood buffy coat from healthy donors; N6 to N8: Normal bone marrow control; PC: Positive control with methylated DNA

Figure 1 Methylation of miR-9-3 and miR-9-1 in controls. A, U- and M-MSP of miR-9-3 and miR-9-1 showed that the positive control (PC) was completely methylated while all 8 normal controls (N1-N8) were completely unmethylated. B, Sequence analysis of the miR-9-3 and miR-9-1 MMSP product from bisulfite-treated positive control DNA respectively showed that the cytosine (C) residues of CpG dinucleotides were methylated and remained unchanged, whereas all the other $C$ residues were unmethylated and were converted to thymidine $[T$, suggesting complete bisulfite conversion and specificity of MSP. MW: Marker; B: Reagent blank; N1 to N3: CD19 sorted B cells of the peripheral blood from healthy donors; N4 to N5: peripheral blood buffy coat from healthy donors; N6 to N8: normal bone marrow control; PC: positive control with methylated DNA.

and miR-9-1 M-MSP products from the bisulfite-treated positive control showed the expected nucleotide changes, confirming complete bisulfite conversion and specificity of MSP (Figure 1B). However, the normal controls including normal CD19+ve B-cells showed methylation of miR-9-2 (Additional file 1: Figure S1A), which was confirmed by direct sequencing (Additional file 1: Figure S1B). Therefore, methylation of miR-9-2 was not further studied.

\section{CLL cell lines}

The profile of miR-9-3 methylation of seven CLL cell lines was shown in Figure 2A. I83-E95 and WAC3CD5+ cell lines showed complete methylation of miR-9-3, 232B4, CLL-AAT and HG3 partial methylation while MEC1 and MEC2 were completely unmethylated. Quantitative bisulfite pyrosequencing confirmed the methylation statuses (MM, MU, UU) of CLL cell lines detected by MSP (Additional file 1: Table S2 and Figure S2A-C). Moreover, apart from I83-E95, in which miR-9-1 was completely methylated, in MEC1, MEC2, 232B4, CLLAAT, HG3 and WAC3CD5+, miR-9-1 was completely unmethylated (Figure 2B).

\section{Primary samples at diagnosis}

Methylation of miR-9-3 was found in thirteen of seventyeight (17\%) patient samples at diagnosis (Figure 3A), while
miR-9-1 methylation was not detected in any of CLL patients (Figure 3B). There was no significant correlation between miR-9-3 methylation and the diagnostic hemoglobin level ( $P=0.14)$, lymphocyte count $(P=0.07)$, age $(P=0.83)$, gender $(\mathrm{P}=0.36)$ or high-risk karyotypes $(\mathrm{P}=0.67)$.

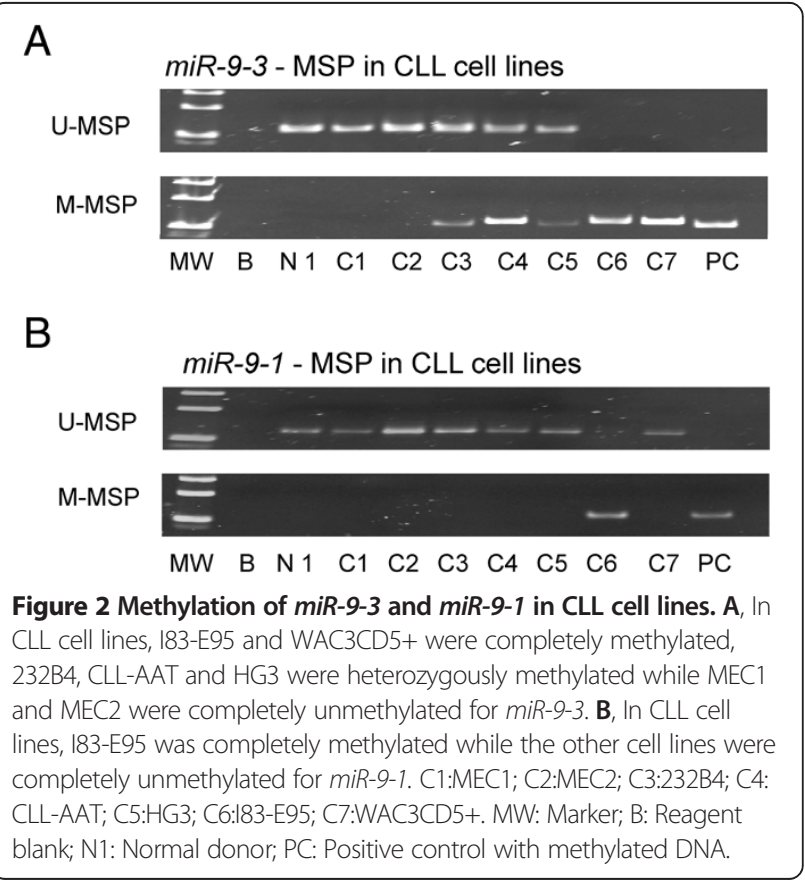




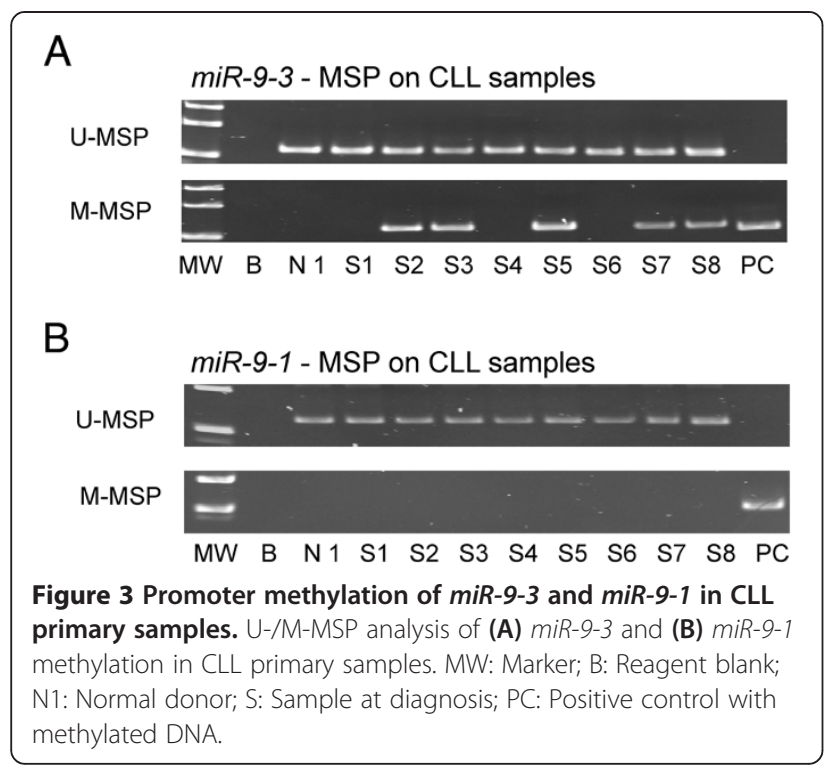

However, a significant association of miR-9-3 methylation with platelet count $(\mathrm{P}=0.03)$ and advanced Rai stage ( $\geq$ stage 2$)(P=0.04)$ was found. The mean OS of CLL patients with and without miR-9-3 methylation were 103 and 87 months respectively $(\mathrm{P}=0.72)$.

\section{5-AzadC treatment of 183-E95 and WAC3CD5+ cells}

I83-E95 and WAC3CD5+ cells were completely methylated for miR-9-3. 5-AzadC treatment of I83-E95 and WAC3CD5 + cells resulted in demethylation of $m i R-9-3$ and the emergence of U-MSP signal on day 5 respectively (Figure 4;
Additional file 1: Figure S2D), with the re-expression of primiR-9-3 as shown by TaqMan stem-loop quantitative RTPCR (Figure 4).

\section{Effect of miR-9 overexpression in I83-E95 cells and WAC3CD5+ cells}

Complete methylation of miR-9-3 was found for the I83E95 cells and WAC3CD5+ cells, leading to its under expression. Upon transfection of precursor $m i R-9$ mimic into I83-E95 cells, overexpression of $m i R-9$ was demonstrated by TaqMan stem-loop quantitative RT-PCR at 48 hours after transfection (Figure 5A). Compared with the negative control transfected with a scrambled oligo at 48 hours, cells overexpressing miR-9 mimic showed a $26 \%$ reduction of cellular proliferation by MTT assay $(P=0.02$, Figure $5 B)$, a $12 \%$ increase of dead cells measured by Trypan blue exclusion assay $(P=0.03$, Figure $5 \mathrm{C})$ and a $13 \%$ increase of apoptosis cells by FITC Annexin V and PI staining ( $\mathrm{P}=$ 0.02 , Figure $5 \mathrm{D})$. Similarly, $m i R-9$ mimics reexpression in WAC3CD5+ cells also led to the inhibition of cell proliferation and increase of cell apoptosis (Additional file 1: Figure S3), indicating that miR-9-3 played a tumor suppressive role in CLL cells. Moreover, miR-9 overexpression in I83-E95 cells led to the downregulation of NFKB1 protein, including the $46 \%$ decrease of the cytoplasmic precursor P105 and 42\% decrease of the corresponding processing product $\mathrm{P} 50$ respectively (Figure $5 \mathrm{E}$ ).

\section{Discussion}

Despite the retrospective nature, this cohort of patients had previously been shown to be typical of CLL, in that
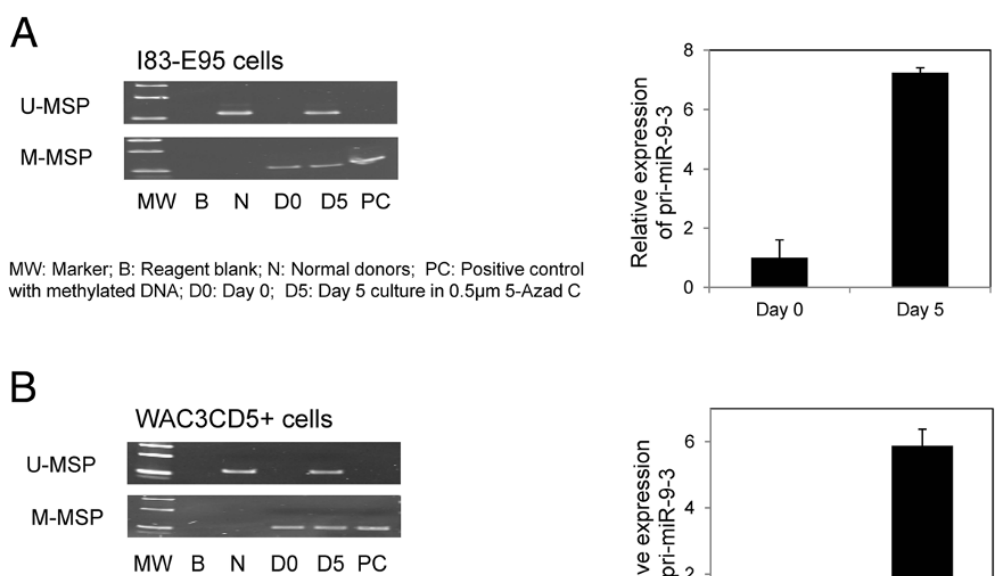

MW: Marker; B: Reagent blank; N: Normal donors; PC: Positive control

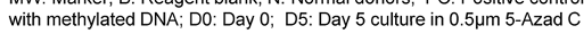

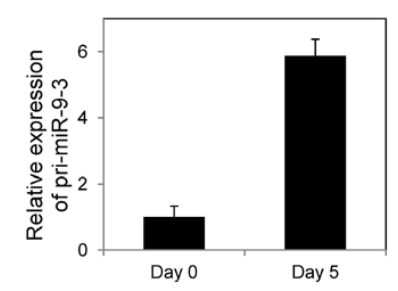

Figure 4 Effect of 5-Aza-2'-deoxycytidine (5-AzadC) treatment on I83-E95 and WAC3CD5+ cells. U-/M-MSP analysis of miR-9-3 promoter methylation status and stem-loop RT-qPCR analysis of the pri-miR-9-3 expression in untreated (A) 183-E95, (B) WAC3CD5+ cells and after treatment with $0.5 \mu \mathrm{M}$ 5-Azad C for 5 days. $\Delta \mathrm{Ct}$, Ct pri-miR-9-3-Ct GAPDH. GAPDH was used as reference for data analysis of pri-miR-9-3 expression by $2^{-\Delta \Delta C T}$ method. 5-AzadC treatment led to the progressive demethylation of miR-9-3 promoter, and re-expression of the pri-miR-9-3 in I83-E95 and WAC3CD5+ cells. Columns represent mean \pm standard deviation of triplicate qPCRs. 

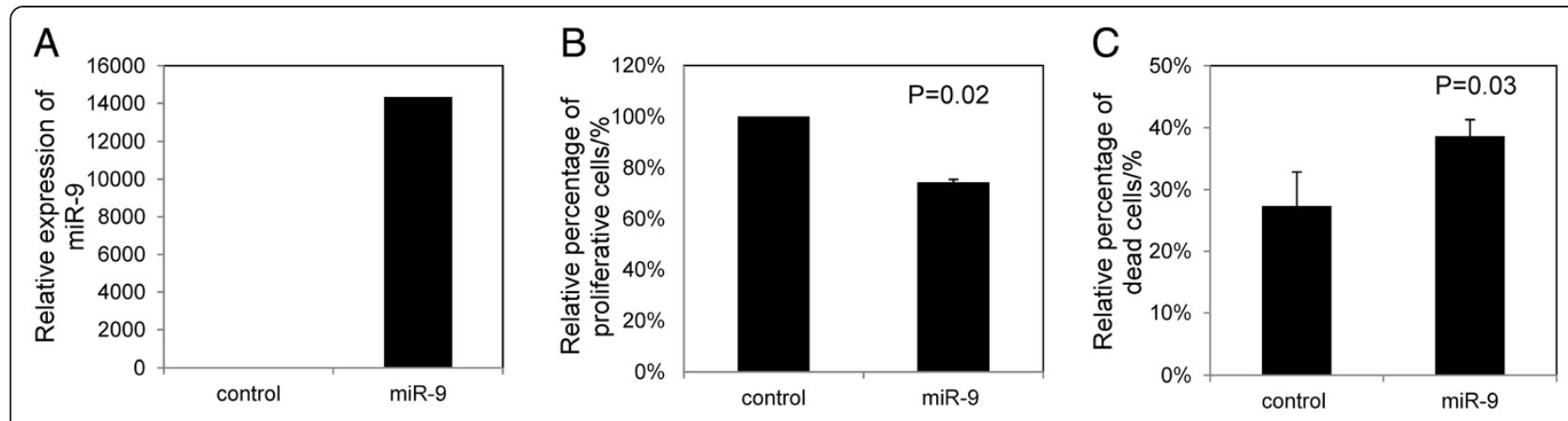

D
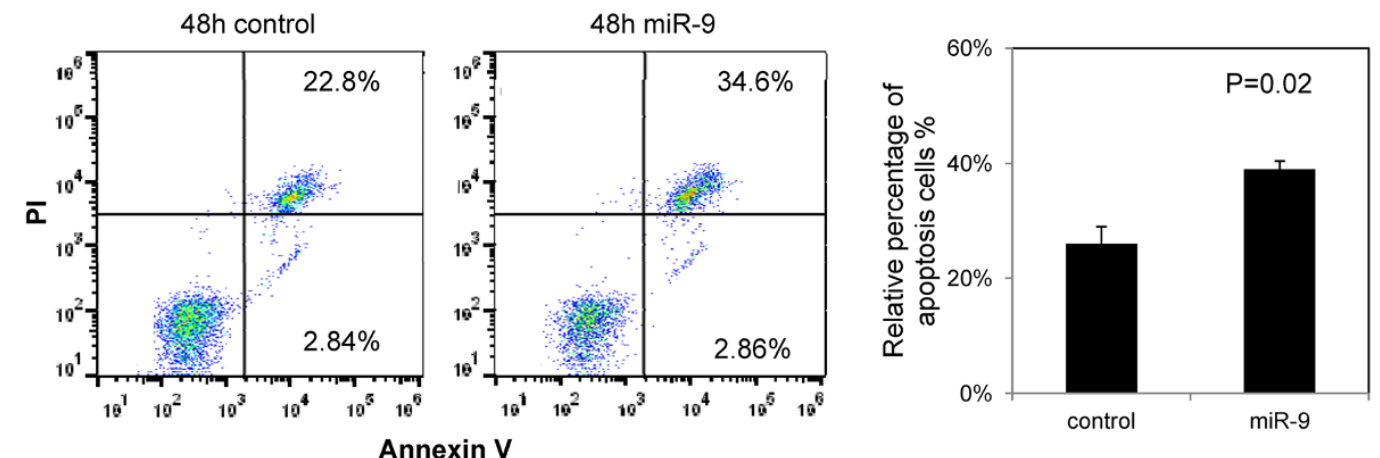

$E$

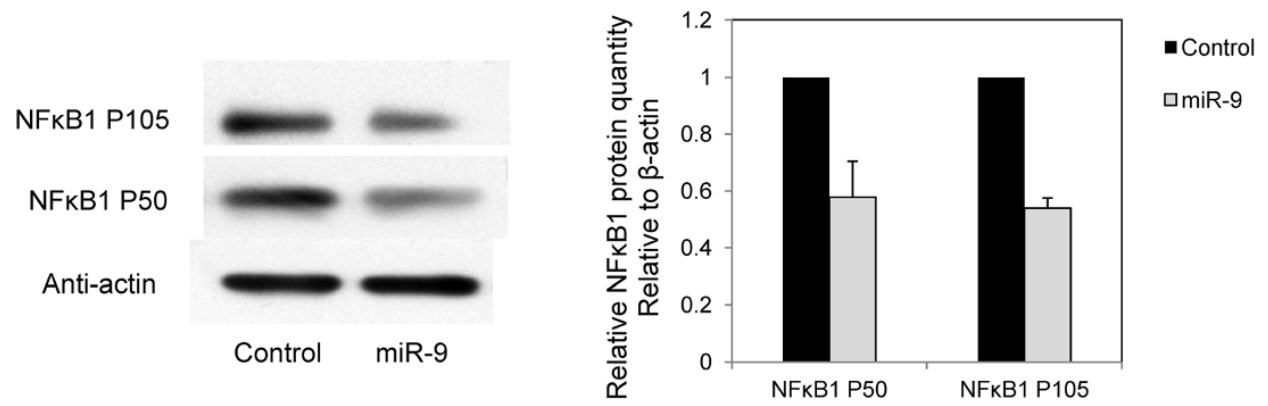

Figure 5 Overexpression of miR-9 in CLL cells. $183-E 95$ cells, completely methylated for miR-9-3, were transfected with miR-9 mimic or scrambled control oligo. Cells were harvested for functional assays 48 hours after transfection. A, Stem-loop RT-qPCR analysis of miR-9 expression at 48 hours after transfection. $\Delta$ Ct, Ct miR-9-Ct RNU48. RNU48 was chosen as reference using the $2^{-\Delta \Delta C T}$ method. B, Cell proliferation of CLL cells in response to overexpression of miR-9 was measured by MTT assay. Column, mean percentage of cell proliferation from three experiments conducted in triplicate; C, Cellular death was measured by Trypan blue exclusion assay. Column, mean percentage of cell death from three experiments conducted in triplicate; D, Cell apoptosis of CLL cells after miR-9 transfection was assessed by flow cytometry using FITC Annexin V and PI staining (left panel: representative result; right panel: values represented mean percentage of cell apoptosis from three experiments performed in triplicate. $\mathbf{E}$, Western blot analysis of NFKB1 (P105/P50) after miR-9 transfection. Total protein was extracted 48 hours after transfection and membranes were probed with antibodies to P105, P50 and Anti-actin. Anti-actin protein was regarded as the endogenous normalizer and the relative NFKB1 (P105/P50) protein level was shown. Error bars represent standard deviation.

patients pursued an indolent course with prolonged survival, which was adversely impacted by advanced Rai stage and high-risk karyotypes.

Firstly, miR-9-3 and miR-9-1 methylation in CLL cell lines was tumor-specific as evidenced by the absence of methylation in normal peripheral blood buffy coat and CD19-sorted B-cells, and normal bone marrow cells. By contrast, miR-9-2 methylation appeared to occur both in normal CD19 + ve B-cells and CLL B-cells, and hence this pattern of methylation is tissue-specific but not tumor-specific [36]. Similarly, miRNAs such as miR-127 and $m i R-373$ have been shown hypermethylated in both normal and tumor cells, and hence represent tissuespecific but not tumor-specific miRNA methylation [36]. On the other hand, a recent study of miRNAs deregulated by either gene hypo- or hyper-methylation in CLL showed methylation of miR-9-2 in CLL [37]. This disparity might be accounted by the use of quantitative 
MassARRAY in their study, in which aberrant methylation of miR-9-2 was defined as a certain level of methylation above that occurring in normal controls. However, as Chinese have a much lower incidence of CLL, whether miR-9-2 methylation in Caucasian patients arose from a primary biological difference between the Asian and Western could not be excluded [38,39].

Furthermore, upon the 5-AzadC treatment of I83-E95 and WAC3CD5+ cells, both of which were homozygously methylated for miR-9-3, emergence of U-MSP signal, and thus demethylation of miR-9-3 promoter, was correlated with pri-miR-9-3 re-expression. Therefore, miR-9-3 methylation is frequent in CLL cell lines, leading to the reversible miRNA silencing.

Moreover, tumor suppressor activity of miR-9-3 was demonstrated in CLL. We showed that restoration of miR-9 in I83-E95 cells harboring complete methylation of $m i R-9-3$ led to reduced cellular proliferation and enhanced apoptosis. In addition, overexpression of miR-9 led to downregulation of NFkB1 (P105/P50), consistent with previous data that $\mathrm{NFKB1}$ was a direct target of miR-9 by translational repression in ovarian cancer cells [24]. On the other hand, while the tumor suppressor role of $m i R-9$, due to epigenetically downregulation, has been reported in some cancers [19,40-43]. miR-9 has also been implicated as an oncomir in other cancers. For example, in breast cancer cells, as a metastasis-promoting miRNA, miR-9 led to enhanced cell motility and hence invasiveness by targeting E-cadherin [21]. In glioblastoma cells, overexpression of miR-9/9* could inhibit the expression of the tumor suppressor gene CAMTA1, leading to enhanced cell survival, implying that it might be an oncomir [23].

Interesting, we noted the significant association of miR-9-3 methylation with advanced Rai stage ( $\geq$ stage 2 ) in CLL patients, which is a poor risk factor for survival. Similarly, miR-9-3 methylation has been shown to be associated with metastatic recurrence in renal cell carcinoma [40], in addition to shorter disease-free and overall survivals in squamous cell lung cancer [41]. However, apart from Rai stage, there was no association between the miR-9-3 methylation and other clinical parameters including age, gender, diagnostic hemoglobin, lymphocyte counts, high-risk karyotypic aberrations or survival. Given the small number of samples in our cohort, the possible role of miR-9-3 as a prognostic marker by impacting on survival requires validation in a larger scale study.

Constitutive activation of NFkB have played roles in carcinogenesis, including stimulating cell proliferation, inhibiting cell apoptosis and increasing tumor metastasis [44]. Upon canonical NFkB activation by cytokines such as IL1, IL-2 or TNFo, NFkB (a dimer comprising P50:P65) is

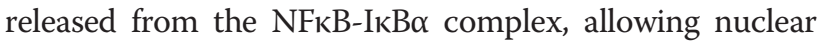

translocation of $\mathrm{NFKB}$ and signaling activation $[45,46]$. $N F \kappa B 1$ gene encodes 2 functional proteins, the cytoplasmic precursor P105 and the corresponding processed product P50. In HEK-293 cells and ovarian cancer ES-2 cells, $N F \kappa B 1$ has been shown to be a direct target of $m i R-9$ by luciferase assay $[24,47]$. Moreover, miR-9 overexpression suppressed tumor cell proliferation in association with repression of NFKB pathway, thereby confirming the tumor suppressive role of $m i R-9$ via the regulation of NFKB signaling in ovarian cancer [24]. Similarly, constitutive activation of $\mathrm{NF}_{\kappa} \mathrm{B}$ activity has been demonstrated in CLL cells, conferring survival benefit through induction of a multitude of anti-apoptotic proteins including X-linked inhibitor of apoptosis protein (XIAP), FLICE-like inhibitory protein (FLIP) and members of the BCL2 family (BCL-XL and A1/BFL1) [48,49]. In our study, we also showed that miR-9 overexpression in I83-E95 cells resulted in downregulation of NFkB1 (P105/P50) protein. Therefore, miR-9-3 methylation may account for constitutive upregulation of $\mathrm{NF}_{\mathrm{K}} \mathrm{B} 1$, and hence constitutive $\mathrm{NF} \mathrm{KB}$ activation in CLL patients.

\section{Conclusions}

Taken together, our results revealed that $m i R-9-3$ was a tumor suppressor miRNA frequently methylated in CLL. miR-9-3 was a tumor suppressor miRNA hypermethylated in CLL, which was associated with down-regulation of NFKB1 protein, and hence might contribute to constitutive activation of NFKB signaling pathway in CLL.

\section{Additional file}

Additional file 1: Figure S1. Methylation of miR-9-2 in controls. (A) M-MSP of miR-9-2 showed that the positive control (PC) and 3 normal CD19 + ve B-cell controls (N1-N3) were completely methylated (B). Sequence analysis of the miR-9-2 M MSP product from bisulfite treated PC DNA and 3 normal CD $19+$ ve B cell controls showed that in normal controls, the cytosine $(\mathrm{C})$ residues of partial $\mathrm{CpG}$ dinucleotides were methylated compared with the PC sequence. (C). Schematic diagram to display the six $\mathrm{CpG}$ dinucleotides illustrated in the sequence. PC showed methylated (black box) of all six CpGs, while normal CD19 + ve B-cell control (1-3) displayed partially miR-9-2 methylation. Table S1: miR-9-1, miR-9-2 and miR-9-3 MSP Primer sequences and the reaction condition. Table S2: Average percent methylation for miR-9-3 in 7 CLL cell lines by pyrosequencing. Figure S2: Quantitative bisulfite pyrosequencing analysis of miR-9-3. The pyrograms showed the methylation intensity on a stretch of 9 neighboring $\mathrm{CpG}$ dinucleotides of (A) Normal control without methylation and positive control with methylated DNA, (B-C) CLL cell lines with defined MSP methylation status (MM, MU and UU) and (D) WAC3CD5+ cells before and after 5-azadC treatment. Figure S3: Overexpression of miR-9 in WAC3CD5+ cells. WAC3CD5+ cells, completely methylated for miR-9-3, which were transfected with miR-9 mimic or scrambled control oligo. (A). miR-9 expression at 48 hours after transfection was measured by Stem-loop RT-qPCR analysis. (B). Cell proliferation of CLL cells in response to overexpression of miR-9 was assessed by MTT assay, whereas (C) cellular death was measured by Trypan blue exclusion assay and (D) the percentage of apoptosis CLL cells was assessed by flow cytometry using FITC Annexin V and PI staining. Error bars represents standard deviation. 


\section{Competing interests}

The authors declare that they have no competing interests.

\section{Authors' contributions}

CSC, YLK conceived of the study, and participated in its design. CSC, CSBK, KFW performed in acquisition of data. LQW performed the experiments. CSC, LQW, KYW participated in data analysis. LQW, CSC, YLK, CSBK, KFW, KYW, MF, GAC are involved in manuscript drafting and revisions. All authors read and approved the final manuscript.

\section{Acknowledgements}

We would like to thank Dr John Byrd, Department of Medicine, Ohio State University, USA for the CLL cell lines (MEC2, WAC3CD5+ and 183-E95) and Prof. Anders Rosén, Department of Clinical \& Experimental Medicine, Linköping University for the CLL cell lines (HG3 and 232B4).

\section{Author details}

${ }^{1}$ Department of Medicine, Queen Mary Hospital, The University of Hong Kong, Hong Kong, China. ${ }^{2}$ Department of Medicine, Pamela Youde Nethersole Hospital, Hong Kong, China. ${ }^{3}$ Department of Pathology, Queen Elizabeth Hospital, Hong Kong, China. ${ }^{4}$ Laboratory for Technologies of Advanced Therapies (LTTA) and Department of Morphology, Surgery and Experimental Medicine, University of Ferrara, Ferrara, Italy. ${ }^{5} \mathrm{MD}$ Anderson Cancer Center, University of Texas, Houston, TX, USA.

Received: 2 August 2013 Accepted: 20 December 2013 Published: 27 December 2013

\section{References}

1. Esteller M: Epigenetics in cancer. N Engl J Med 2008, 358:1148-1159.

2. Chim CS, Liang R, Kwong YL: Hypermethylation of gene promoters in hematological neoplasia. Hematol Oncol 2002, 20:167-176.

3. Jones PA, Baylin SB: The epigenomics of cancer. Cell 2007, 128:683-692

4. Gonzalez-Zulueta M, Bender CM, Yang AS, Nguyen TD, Beart RW, Van Tornout JM, Jones PA: Methylation of the $5^{\prime} \mathrm{CpG}$ island of the p16/ CDKN2 tumor suppressor gene in normal and transformed human tissues correlates with gene silencing. Cancer Res 1995, 55:4531-4535.

5. Chim CS, Pang R, Fung TK, Choi CL, Liang R: Epigenetic dysregulation of Wnt signaling pathway in multiple myeloma. Leukemia 2007, 21:2527-2536.

6. Chim CS, Fung TK, Wong KF, Lau J, Liang R: Frequent DAP kinase but not p14 or Apaf-1 hypermethylation in B-cell chronic lymphocytic leukemia. J Hum Genet 2006, 51:832-838.

7. Raval A, Tanner SM, Byrd JC, Angerman EB, Perko JD, Chen S-S, Hackanson B, Grever MR, Lucas DM, Matkovic JJ, et al: Downregulation of DeathAssociated Protein Kinase 1 (DAPK1) in Chronic Lymphocytic Leukemia. Cell 2007, 129:879-890.

8. Chen SS, Claus R, Lucas DM, Yu L, Qian J, Ruppert AS, West DA, Williams KE, Johnson AJ, Sablitzky F: Silencing of the inhibitor of DNA binding protein 4 (ID4) contributes to the pathogenesis of mouse and human CLL. Blood 2011, 117:862-871.

9. Liu TH, Raval A, Chen SS, Matkovic JJ, Byrd JC, Plass C: CpG island methylation and expression of the secreted frizzled-related protein gene family in chronic lymphocytic leukemia. Cancer Res 2006, 66:653-658.

10. Raval A, Lucas DM, Matkovic JJ, Bennett KL, Liyanarachchi S, Young DC, Rassenti L, Kipps TJ, Grever MR, Byrd JC: TWIST2 demonstrates differential methylation in immunoglobulin variable heavy chain mutated and unmutated chronic lymphocytic leukemia. J Clin Oncol 2005, 23:3877-3885.

11. Chantepie SP, Vaur D, Grunau C, Salaun V, Briand M, Parienti JJ, Heutte N, Cheze S, Roussel M, Gauduchon P, et al: ZAP-70 intron1 DNA methylation status: determination by pyrosequencing in $B$ chronic lymphocytic leukemia. Leuk Res 2010, 34:800-808.

12. Calin GA, Croce CM: MicroRNA signatures in human cancers. Nat Rev Cancer 2006, 6:857-866.

13. Bartel DP: MicroRNAs: target recognition and regulatory functions. Cell 2009, 136:215-233

14. Chen CZ: MicroRNAs as oncogenes and tumor suppressors. N Engl J Med 2005, 353:1768-1771.

15. Zhang $B$, Pan $X$, Cobb GP, Anderson TA: microRNAs as oncogenes and tumor suppressors. Dev Biol 2007, 302:1-12.
16. Wong $K Y$, Huang $X$, Chim CS: DNA methylation of microRNA genes in multiple myeloma. Carcinogenesis 2012, 33:1629-1638.

17. Yim RLH, Kwong YL, Wong KY, Chim CS: DNA methylation of tumor suppressive miRNAs in non-Hodgkin's lymphomas. Front Genet 2012, 3:223.

18. Wang LQ, Liang R, Chim CS: Methylation of tumor suppressor microRNAs: lessons from lymphoid malignancies. Expert Rev Mol Diagn 2012, 12:755-765.

19. Tsai KW, Liao YL, Wu CW, Hu LY, Li SC, Chan WC, Ho MR, Lai CH, Kao HW, Fang WL: Aberrant hypermethylation of miR-9 genes in gastric cancer. Epigenetics 2011, 6:1189-1197.

20. Z Zhang H, Qi M, Li S, Qi T, Mei H, Huang K, Zheng L, Tong Q: microRNA-9 targets matrix metalloproteinase 14 to inhibit invasion, metastasis, and angiogenesis of neuroblastoma cells. Mol Cancer Ther 2012, 11:1454-1466.

21. Ma L, Young J, Prabhala H, Pan E, Mestdagh P, Muth D, Teruya-Feldstein J, Reinhardt F, Onder TT, Valastyan S: miR-9, a MYC/MYCN-activated microRNA, regulates E-cadherin and cancer metastasis. Nat Cell Biol 2010, 12:247-256.

22. Nass D, Rosenwald S, Meiri E, Gilad S, Tabibian-Keissar H, Schlosberg A, Kuker H, Sion-Vardy N, Tobar A, Kharenko O: MiR-92b and miR-9/9* are specifically expressed in brain primary tumors and can be used to differentiate primary from metastatic brain tumors. Brain Pathol 2009 19:375-383.

23. Schraivogel D, Weinmann L, Beier D, Tabatabai G, Eichner A, Zhu JY, Anton $M$, Sixt M, Weller M, Beier CP: CAMTA1 is a novel tumour suppressor regulated by miR-9/9* in glioblastoma stem cells. EMBO J 2011, 30:4309-4322

24. Guo LM, Pu Y, Han Z, Liu T, Li YX, Liu M, Li X, Tang H: MicroRNA-9 inhibits ovarian cancer cell growth through regulation of NF-kB1. FEBS J 2009, 276:5537-5546.

25. Hallek M, Cheson BD, Catovsky D, Caligaris-Cappio F, Dighiero G, Döhner H, Hillmen P, Keating MJ, Montserrat E, Rai KR, Kipps TJ: Guidelines for the diagnosis and treatment of chronic lymphocytic leukemia: a report from the International Workshop on Chronic Lymphocytic Leukemia updating the National Cancer Institute-Working Group 1996 guidelines. Blood 2008, 111:5446-5456.

26. Jaffe ES: Pathology and genetics of tumours of haematopoietic and lymphoid tissues. Lyon: LARC Press; 2001.

27. Stacchini A, Aragno M, Vallario A, Alfarano A, Circosta P, Gottardi D, Faldella A, Rege-Cambrin G, Thunberg U, Nilsson K: MEC1 and MEC2: two new cell lines derived from B-chronic lymphocytic leukaemia in prolymphocytoid transformation. Leuk Res 1999, 23:127-136.

28. Wendel-Hansen V, Sällström J, De Campos-Lima P, Kjellström G, Sandlund A, Siegbahn A, Carlsson M, Nilsson K, Rosen A: Epstein-Barr virus (EBV) can immortalize B-cll cells activated by cytokines. Leukemia 1994, 8:476-484.

29. Rosén A, Bergh AC, Gogok P, Evaldsson C, Myhrinder AL, Hellqvist E, Rasul A, Björkholm M, Jansson M, Mansouri L: Lymphoblastoid cell line with B1 cell characteristics established from a chronic lymphocytic leukemia clone by in vitro EBV infection. Oncol Immunol 2012, 1:18-27.

30. Herman JG, Graff JR, Myöhänen S, Nelkin BD, Baylin SB: Methylationspecific PCR: a novel PCR assay for methylation status of CPG islands. Proc Natl Acad Sci USA 1996, 93:9821-9826.

31. Wong KY, Yim RLH, So CC, Jin DY, Liang R, Chim CS: Epigenetic inactivation of the MIR34B/C in multiple myeloma. Blood 2011, 118:5901-5904.

32. Livak KJ, Schmittgen TD: Analysis of Relative Gene Expression Data Using Real-Time Quantitative PCR and the $2{ }^{\Delta \Delta}$ CT Method. Methods 2001, 25:402-408.

33. Wong KY, Liang R, So CC, Jin DY, Costello JF, Chim CS: Epigenetic silencing of MIR203 in multiple myeloma. Br J Haematol 2011, 154:569-578.

34. Mosmann T: Rapid colorimetric assay for cellular growth and survival: application to proliferation and cytotoxicity assays. J Immunol Methods 1983, 65:55-63.

35. van Engeland M, Ramaekers FC, Schutte B, Reutelingsperger CP: A novel assay to measure loss of plasma membrane asymmetry during apoptosis of adherent cells in culture. Cytometry 1996, 24:131-139.

36. Lujambio A, Ropero S, Ballestar E, Fraga MF, Cerrato C, Setién F, Casado S, Suarez-Gauthier A, Sanchez-Cespedes M, Gitt A, et al: Genetic unmasking of an epigenetically silenced microRNA in human cancer cells. Cancer Res 2007, 67:1424-1429.

37. Baer C, Claus R, Frenzel LP, Zucknick M, Park YJ, Gu L, Weichenhan D, Fischer M, Pallasch CP, Herpel E, et al: Extensive Promoter DNA 
Hypermethylation and Hypomethylation Is Associated with Aberrant MicroRNA Expression in Chronic Lymphocytic Leukemia. Cancer Res 2012, 72:3775-3785

38. Chim CS, Fung TK, Wong KF, Lau JS, Law M, Liang R: Methylation of INK4 and CIP/KIP families of cyclin-dependent kinase inhibitor in chronic lymphocytic leukaemia in Chinese patients. J Clin Pathol 2006, 59:921-926

39. Dores GM, Anderson WF, Curtis RE, Landgren O, Ostroumova E, Bluhm EC, Rabkin CS, Devesa SS, Linet MS: Chronic lymphocytic leukaemia and small lymphocytic lymphoma: overview of the descriptive epidemiology. Br J Haematol 2007, 139:809-819.

40. Hildebrandt M, Gu J, Lin J, Ye Y, Tan W, Tamboli P, Wood C, Wu X: Hsa-miR9 methylation status is associated with cancer development and metastatic recurrence in patients with clear cell renal cell carcinoma. Oncogene 2010, 29:5724-5728.

41. Heller G, Weinzierl M, Noll C, Babinsky V, Ziegler B, Altenberger C, Minichsdorfer C, Lang G, Döme B, End-Pfützenreuter A, et al: Genome-Wide miRNA Expression Profiling Identifies miR-9-3 and miR-193a as Targets for DNA Methylation in Non-Small Cell Lung Cancers. Clin Cancer Res 2012, 18:1619-1629.

42. Lujambio A, Calin GA, Villanueva A, Ropero S, Sánchez-Céspedes M, Blanco D, Montuenga LM, Rossi S, Nicoloso MS, Faller WJ, et al: A microRNA DNA methylation signature for human cancer metastasis. Proc Natl Acad Sci USA 2008, 105:13556-13561.

43. Bandres E, Agirre X, Bitarte N, Ramirez N, Zarate R, Roman-Gomez J, Prosper $\mathrm{F}$, Garcia-Foncillas J: Epigenetic regulation of microRNA expression in colorectal cancer. Int I Cancer 2009, 125:2737-2743.

44. Karin M, Cao Y, Greten FR, Li Z-W: NF-KB in cancer: from innocent bystander to major culprit. Nat Rev Cancer 2002, 2:301-310.

45. Van Antwerp DJ, Martin SJ, Kafri T, Green DR, Verma IM: Suppression of TNF-a-Induced Apoptosis by NF-kB. Science 1996, 274:787-789.

46. Tak PP, Firestein GS: NF-kappaB: a key role in inflammatory diseases. J Clin Invest 2001, 107:7-12

47. Bazzoni F, Rossato M, Fabbri M, Gaudiosi D, Mirolo M, Mori L, Tamassia N, Mantovani A, Cassatella MA, Locati M: Induction and regulatory function of miR-9 in human monocytes and neutrophils exposed to proinflammatory signals. Proc Natl Acad Sci U S A 2009, 106:5282-5287.

48. Furman RR, Asgary Z, Mascarenhas JO, Liou H-C, Schattner EJ: Modulation of NF-KB Activity and Apoptosis in Chronic Lymphocytic Leukemia B Cells. J Immunol 2000, 164:2200-2206.

49. Cuni S, Perez-Aciego P, Perez-Chacon G, Vargas JA, Sanchez A, Martin-Saavedra FM, Ballester S, Garcia-Marco J, Jorda J, Durantez A: A sustained activation of $\mathrm{PI}$ KK/NF-KB pathway is critical for the survival of chronic lymphocytic leukemia B cells. Leukemia 2004, 18:1391-1400.

doi:10.1186/1476-4598-12-173

Cite this article as: Wang et al:: Epigenetic inactivation of miR-9 family microRNAs in chronic lymphocytic leukemia - implications on constitutive activation of NFKB pathway. Molecular Cancer 2013 12:173.

\section{Submit your next manuscript to BioMed Central and take full advantage of:}

- Convenient online submission

- Thorough peer review

- No space constraints or color figure charges

- Immediate publication on acceptance

- Inclusion in PubMed, CAS, Scopus and Google Scholar

- Research which is freely available for redistribution

Submit your manuscript at www.biomedcentral.com/submit
Ciomed Central 